\title{
PENGEMBANGAN LEMBAR KERJA SPATIAL THINKING to SOLVING PROBLEM PADA PROGRAM STUDI PENDIDIKAN GEOGRAFI
}

\author{
Armin Subhani ${ }^{1}$, Sri Agustina ${ }^{2}$ \\ 1 Program Studi Pendidikan Geografi Universitas Hamzanwadi \\ Email: armin@hamzanwadi.ac.id
}

\begin{abstract}
ABSTRAK
Berpikir spasial merupakan kompetensi utama yang harus dimiliki mahasiswa dalam menyelesaikan masalah geografi. Berdasarkan kebutuhan tersebut, penelitian ini bertujuan untuk mengembangkan lembar kerja mahasiswa pada mata kuliah hidrologi dasar. Lembar kerja dirancang berbasis kemampuan berpikir spasial (spatial thinking) dan penyelesaian masalah (solving problem). Metode pengembangannya mengikuti prosedur Dick dan Carey yang terdiri dari Sembilan langkah dan dibagi empat tahap; (1) perancangan, (2) pngembangan, (3) validasi dan uji produk. Data yang dikumpulkan terdiri dari data uji validasi dan uji coba lapangan. Validasi melibatkan ahli teknologi pembelajaran, ahli materi Hidrologi, dan ahli bahasa. Uji coba lapang terbatas melibatkan I kelas yang terdiri dari 10 orang mahasiswa. Hasil analisis data menunjukkan, validasi kelayakan penyajian dari ahli teknologi pembelajaran dikategorikan baik dengan skor 3. Berdasarkan tabel keputusan, nilai tersebut menunjukkan lembar kerja hasil pengembangan dapat digunakan, tetapi perlu direvisi. Validasi kelayakan isi/materi diperoleh skor 3 dinilai cukup baik. Berdasarkan tabel keputusan, nilai tersebut menunjukkan lembar kerja hasil pengembangan dapat digunakan tapi perlu direvisi juga. Validasi kelayakan bahasa dari ahli bahasa, diperoleh skor 4,3, skor tersebut dinilai sangat baik, berdasarkan tabel keputusan, lembar kerja tidak perlu direvisi dari segi bahasa. Kemudian dari hasil uji coba lapangan, diperoleh skor 4,5 kategori sangat baik, dan menurut tabel keputusan, lembar kerja tidak perlu direvisi, layak digunakan dari sisi kemudahan memahami, kemenarikan, dan keterbacaan.
\end{abstract}

Kata Kunci: Lembar kerja, Spatial Thinking, Solving Problem

\section{PENDAHULUAN}

Salah satu fenomena geografis dalam kajian geografi adalah hidrosfer. Masalah hidrosfer pada suatu wilayah dapat dijelaskan dengan mengetahui keberadaan air di bumi, jumlahnya, sebarannya, kualitas, dan interaksinya dengan lingkungan hidup. Untuk mengetahui semua itu, Geografi sebagai ilmu membutuhkan pemahaman Hidrologi secara baik (Khafid, 2013). Artinya Hidrologi dalam ilmu Geografi berperan sebagai ilmu bantu.
Hidrologi merupakan bagian dari kajian geografi fisik yang membahas air di bumi dengan penekanan khusus pada distribusi, sifat-sifat, fenomena, terdapatnya air di bumi, deskripsi bumi dalam hubungannya dengan air, dan efek fisik air di bumi serta hubungannya antara air dengan kehidupan di bumi (Linsley, 1975).Tiga perspektif geografi fisik, yaitu keruangan, fisik, dan lingkungan (Gabler et al, 2009). Perspektif keruangan menyorot hidrologi dari lima isu, yaitu 
lokasi, (2) karakteristik fisik lokasi, (3) distribusi dan pola spasial, (4) interaksi spasial, dan (5) perubahan spasial. Perspektif fisik menekankan hidrologi sebagai bagian dari objek material geografi, dan perspektif lingkungan membahas timbal balik antara lingkungan manusia dengan lingkungan fisik. Ruang lingkup kajian tersebut secara umum dituangkan dalam tujuan pembelajaran hidrologi di program studi pendidikan geografi Universitas Hamzanwadi.

Tujuan pembelajaran diarahkan agar mahasiswa mampu memahami konsep hidrologi dalam perspektif geografi, dan mampu menerapkan konsep tersebut dalam mengkaji fenomena permasalahan air dan interaksinya dengan lingkungan untuk pembangunan berkelanjutan (Subhani, 2017). Tujuan akan lebih mudah tercapai jika didukung perangkat pembelajaran seperti bahan ajar. Untuk keperluan tersebut, peneliti juga sudah melakukan pengembangan bahan ajar berbentuk buku cetak dan telah diuji layak dari sisi kemenarikan, keterbacaan, dan kemudahan difahami. Bahan ajar juga telah divalidasi oleh tiga ahli, yakni ahli pembelajaran, isi/materi hidrologi, dan juga ahli bahasa. Hasil penelitian pengembangan telah dipublikasikan di jurnal internasional (Subhani et al, 2017).

$$
\text { Bahan ajar tersebut }
$$
mengarahkan agar mahasiswa memiliki keterampilan berpikir spasial (spatial thinking) dalam memecahkan permasalahan fenomena hidrosfer. Berpikir spasial dianggap sebagai kompetensi penting yang harus dikuasai dan merupakan kunci sukses mahasiswa geografi (Metoyer \& Bednarz, 2017). Berpikir spasial didefinisikan sebagai kemampuan kognitif yang dapat digunakan untuk mentransformasi dan mengkombinasikan informasi dengan dasar tiga komponen; (a) konsep keruangan, (b) alat perepresentasian, dan (c) proses berpikir (NCR, 2006).

Penelitian terkait buku teks/bahan ajar yang mendorong spatial thinking masih terbilang sedikit, bahkan (Scholz et al, 2014) menjelaskan buku teks/bahan ajar untuk spatial thinking skills masih tergolong baru. Masih banyak celah untuk mengembangkan bahan ajar yang berorientasi pada spatial thinking, oleh karena itu penelitian ini bermaksud menyempurnakan hasil penelitian pengembangan bahan ajar sebelumnya (Subhani et al, 2017). Penyempurnaan dilakukan dengan mengembangkan Lembar Kerja Mahasiswa (LKM) yang mendorong berpikir spasial dalam menyelesaikan masalah fenomena hidrosfer dalam kajian Geografi. Lembar kerja tersebut dinamakan sebagai "spatial thinking to solving problem (STSP)".

Lembar kerja STSP diharapkan mendorong mahasiswa untuk aktif melakukan kegiatan tertentu, sering disebut sebagai geography activities (aktifitas geografi). Aktifitas yang dimaksud adalah, serangkain prosedur kerja yang telah dirancang secara sistematis untuk mencapai kompetensi tertentu. Dalam konteks bahan ajar yang telah dikembangkan, setiap akhir bab diberikan tugas untuk menyusun suatu makalah terkait permasalahan hidrosfer. Untuk menyusun makalah tersebut diperlukan langkah-langkah kerja yang tertuang dalam lembar kerja STSP. Dengan demikian makalah yang 
dihasilkan dapat mencerminkan komptensi berpikir spasial dan kemampuan merumuskan penyelesaian masalah.

Fokus masalah yang akan dirumuskan penyelesaiannya dalam lembar kerja STSP, tentang masalah krisis air bersih di Kecamatan Jerowaru Lombok Timur. Berdasarkan data dari Badan Penanggulangan Bencana Daerah (BPBD) Lotim, dari 15 desa yang ada di Kecamatan Jerowaru, 12 desa selalu kekurangan air bersih untuk minum dan masak. Sebagian desa tersebut berada di kawasan pantai, jika musim hujan air hujan yang digunakan keruh dan musim kemarau membeli air patungan dengan harga Rp 150.000/tangki. Di sebagian yang lain air sumur mengering, sehingga setiap tahun pemerintah selalu memberikan bantuan air bersih (Lombok Post, 2017).

Penyelesaian masalah melalui pembelajaran memberikan pengalaman bermakna dan dapat memotivasi mahasiswa untuk mengaplikan konsep diperkuliahan sesuai dengan realita yang ada. Salah satunya melalui lembar kerja mahasiswa, penggunaan lembar kerja (worksheet) untuk menunjang pembelajaran, jamak dilakukan oleh berbagai disiplin ilmu. Misalnya lembar kerja untuk pendidikan matematika dan sains (Karsli \& Sahin, 2009; Bakirci et al, 2011; Rahmi dkk, 2014;), pendidikan farmasi (Trewet et al, 2013), pendidikan fisika (Kolumuk et al, 2012; Astutik et al, 2017), pendidikan sejarah (Ayva, 2012), dan pendidikan geografi (Utami et al, 2016). Semua penelitian tersebut mencerminkan bahwa penggunaan lembar kerja dalam pembelajaran masih dianggap relevan sampai saat ini.

Beradasarkan urgensi dan relevansi pada latar belakang masalah, penelitian ini memiliki 2 tujuan menghasilkan model lembar kerja Spatial Thinking to Solving Problem (STSP) yang layak digunakan.

\section{METODE PENELITIAN Model Pengembangan}

Model yang digunakan dalam penelitian ini mengacu pada model prosedural Dick \& Carey (2001), model ini sering dipakai dalam penelitian dan pengembangan secara luas.

Langkah-langkah pada model tersebut terdiri dari sepuluh langkah, yaitu: 1) analisis kebutuhan dan tujuan, 2) analisis pembelajaran, 3) analisis pembelajar dan koteks, 4) merumuskan tujuan pembelajaran performansi, 5) mengembangkan instrumen, 6) mengembangkan strategi pembelajaran, 7) memilih dan mengembangkan bahan pembelajaran, 8) merancang dan melaksanakan evaluasi formatif, 9) melakukan revisi, 10) evaluasi sumatif. Untuk keperluan pengembangan ini hanya menggunakan sampai pada langkah kesembilan, yaitu evaluasi formatif dimana rancangan sudah dianggap selesai.

\section{Prosedur Pengembangan}

Sembilan langkah yang digunakan dalam Dick \& Carey (2001) menjadi acuan prosedur pengembangan. Walaupun demikian, langkah-langkah dalam penelitian dan pengembangan dapat dipilih 
sesuai dengan kebutuhan peneliti/pengembang sesuai dengan kebutuhan, kondisi, dan kendala yang dihadapi. Oleh karena itu Sembilan langkah tersebut dimodifikasi menjadi tiga tahapan utama, yaitu perancangan, pengembangan produk, validasi dan uji produk tanpa menghilangkan esensi dari sembilan langkah yang digunakan.

\section{Uji Coba}

\section{Desain Uji Coba}

Uji coba dilakukan untuk mengetahui tingkat kemenarikan, keterbacaan, dan kemudahan memahami lembar kerja. Tahapan ini dilakukan setelah hasil validasi dari ahli dinyatakan layak dan dilakukan revisi jika diperlukan. Subjek uji coba melibatkan 10 orang mahasiswa.

\section{Jenis Data dan Sumber Data}

Data yang dikumpulkan dalam tahap hasil uji coba ini adalah :

1) Kelayakan isi lembar kerja yang diperoleh dari ahli pembelajaran geografi.

2) Kelayakan desain lembar kerja diperoleh dari ahli desain pembelajaran.

3) Kelayakan bahasa lembar kerja diperoleh dari ahli bahasa.

4) Kemenarikan, keterbacaan, dan kemudahan memahami lembar kerja diperoleh dari mahasiswa.

\section{Instrumen Pengumpulan Data}

Untuk mendapatkan 5 jenis data di atas digunakan 4 jenis angket dan 1 paket lembar kerja bersama instrumen penilaiannya.
1) Angket Penilaian untuk Ahli Desaian Pembelajaran

2) Angket Penilaian untuk Ahli Materi/Isi Geografi.

3) Angket Penilaian untuk Ahli Bahasa.

4) Angket Penilaian untuk Mahasiswa.

\section{Analisis Data}

Data dari 4 jenis angket di atas kemudian dianalisis dengan cara analisis skor.

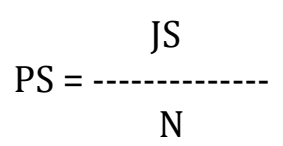

Keterangan:

$\mathrm{N}$ : Jumlah seluruh item angket

JS : Jumlah skor jawaban

responden

PS : Perolehan skor

Tabel 4.1 Tingkat Pencapaian, Kualifikasi, dan Keputusan

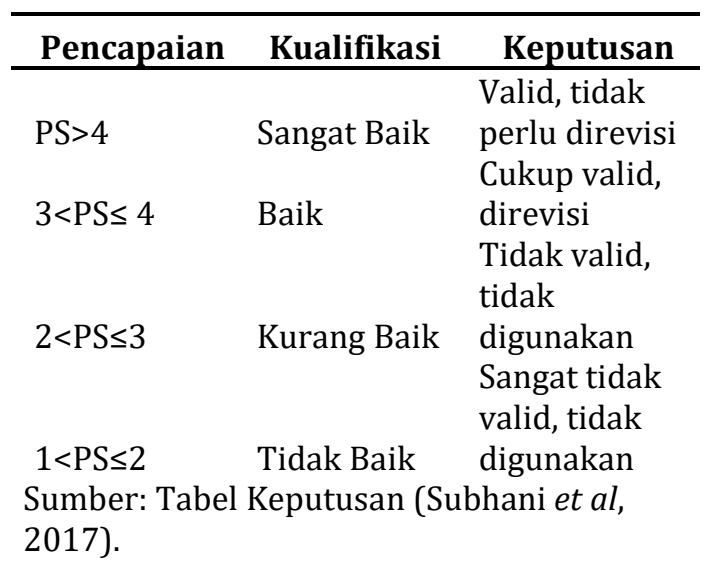

HASIL

Pada metode dijelaskan serangkaian prosedur pengembangan yang mencakup 3 tahapan utama, perancangan, pengembangan, dan uji produk. Namun pada penelitian ini 
ditambah dengan uji efektivitas produk. Kemajuan penelitian ini sudah sampai pada tahap pengembangan dengan uraian sebagai berikut:

\section{Perancangan}

\section{Rasional}

Lembar kerja merupakan salah satu perangkat pembelajaran yang urgen dalam pencapaian tujuan pembelajaran. Identifikasi tujuan bisa dilakukan dengan mencermati kebijakan pemerintah mengenai Standar Nasional Perguruan Tinggi (SNPT) yang tertuang dalam Peraturan Menteri Pendidikan dan Kebudayaan No. 49 Tahun 2014 tentang Standar Kompetensi Lulusan (SKL). Kebijakan tersebut menjelaskan bahwa, standar kompetensi lulusan merupakan kriteria minimal tentang kualifikasi kemampuan lulusan yang mencakup sikap, pengetahuan, dan keterampilan yang dinyatakan dalam rumusan capaian pembelajaran/tujuan pembelajaran. Dalam hal ini program studi diwajibkan menyusun tujuan pembelajaran sebagai rumusan capaian pembelajaran setiap mata kuliah.

Selanjutnya, berdasarkan pengelompokan rumpun mata kuliah (Dikti, 2012) kedudukan Matakuliah Hidrologi pada Program Studi Pendidikan Geografi termasuk dalam Mata Kuliah Bidang Keahlian (MKBK). Dengan demikian, Hidrologi adalah mata kuliah yang berkaitan dengan kompetensi akademik subtansi kajian utama Geografi (Hidrologi sebagai bagian Geografi Fisik).

Berdasarkan kebutuhan

tersebut, lembar kerja model STSP dipandang relevan sebagai model pengorganisasian tugas terstruktur dalam bahan ajar Hidrologi. Strategi pengorganisasian bermakna cara untuk membuat urutan atau membuat sintesis fakta, konsep, prosedur, dan prinsip yang berkaitan. Model ini berbentuk lembar kerja tugas terstruktur.

Secara umum model lembar kerja $\boldsymbol{S T S P ,}$ memiliki karakteristik sebagai berikut:

1) Menekankan

tercapainya tujuan pembelajaran.

2) Memunculkan sudut pandang geografi (lokasi, distribusi, karakteristik, interaksi lingkungan) dalam mendeskripsikan hidrologi sebagai bagian dari geografi fisik.

3) Mendorong pembelajaran aktif melalui diskusi, tugas, dan latihan pemecahan masalah.

4) Mengarahkan untuk tercapainya pemahaman konsep dan aplikasinya.

5) Mengarahkan penggunaan instrument geografi (peta, citra satelit, dan lain-lain).

6) Menghendaki penyampaian materi yang jelas.

Tujuan

Berdasarkan rasionel tersebut, lembar kerja STSP mengarahkan mahasiswa pada tujuan pencapaian pemahaman konsep hidrologi dalam perspektif geografi, dan mampu menerapkan konsep tersebut dalam mengkaji fenomena permasalahan air dan interaksinya dengan lingkungan untuk pembangunan berkelanjutan. 
Ruang lingkup

Mengingat kajian hidrologi sangat luas, dan berdasarkan keluasan, kedalaman materi di LPTK Geografi, dan konteks permasalahan yang dikaji maka ruang lingkup lembar kerja yang disajikan model STSP mencakup:

1) Pengantar Hidrologi

2) Hujan (presipitasi)

3) Penguapan (evaporasi).

4) Air tanah (groundwater).

5) Air permukaan (sungai dan danau).

6) Kualitas air.

7) Permasalahan yang menjadi fokus enam bahasan di atas adalah sesuai dengan permasalahan daerah setempat yaitu krisis air bersih di kecamatan Jerowaru.

\section{Pengembangan}

Dasar pengembangan adalah hasil pada tahap perancangan. Hasil pengembangan dapat diuraikan sebagai berikut;

a. Desain sampul lembar kerja

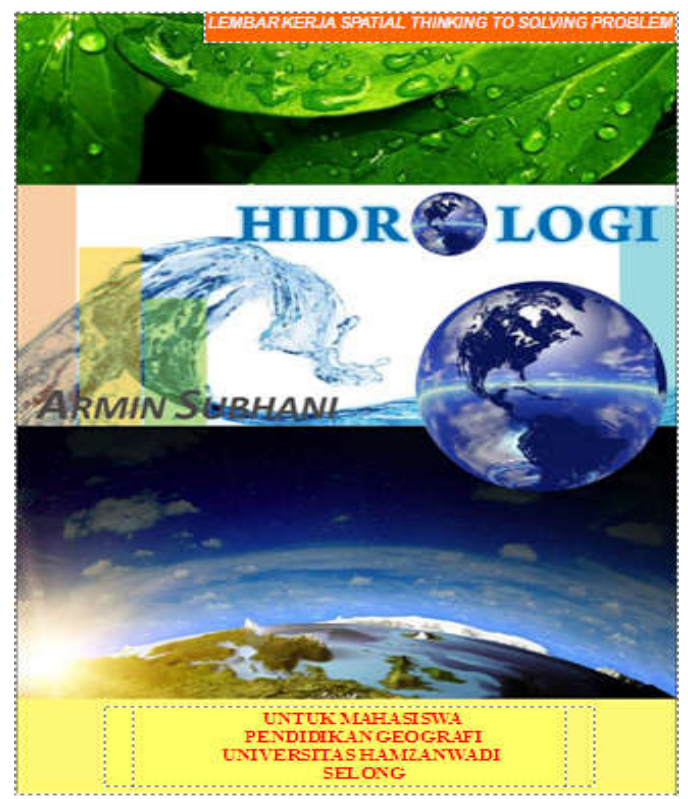

Gambar 1. Desain sampul lembar kerja b. Struktur penyajian

1) Judul dan No aktivitas

2) Tujuan pembelajaran

3) Pengantar permasalahan

4) Langkah kerja

5) Bahan dan alat

6) Atitude Geography Spot (AGS)

7) Keterampilan STSP

\section{Sajian dan Analisis Data}

Sebagaimana telah disampaikan pada bab metode, uji produk awal melalui 2 (dua) tahapan, yaitu uji validasi ahli dan uji formatif (terbatas). Validasi melibatkan tiga ahli, seperti ahli teknologi pembelajaran, ahli materi hidrologi, dan ahli bahasa. Sedangkan uji terbatas melibatkan 10 mahasiswa Universitas Hamzanwadi.

\section{a. Uji Validasi Ahli}

Hasil yang didapatkan dari para ahli berupa kelayakan penyajian, kelayakan materi, dan kelayakan bahasa. Berdasarkan penilaian tersebut dapat diketahui 4 komponen dinilai baik, 2 komponen dinilai cukup, dan 1 komponen dinilai kurang. Khusus lembar kerja STSP dinilai cukup baik, namun secara umum produk bahan ajar Hidrologi dikategorikan baik (skor 3,43), berdasarkan tabel keputusan nilai tersebut dalam kategori valid, perlu direvisi. Beberapa catatan yang muncul untuk perbaikan seperti terlihat pada kolom masukan, langsung diperbaiki sesuai dengan saran validator. Khusus untuk komponen yang dinilai kurang juga diperbaiki, untuk mendapatkan hasil yang lebih baik 
Tabel 1 Hasil Uji Validasi Kelayakan Bahan Ajar dan Lembar Kerja dari Ahli Teknologi Pembelajaran.

\begin{tabular}{|c|c|c|c|c|c|}
\hline No & Komponen & Skor & $\begin{array}{l}\text { Kategori } \\
\text { Penilaian }\end{array}$ & Masukan & Tindak Lanjut \\
\hline 1 & Kejelasan judul & 4 & Baik & \multirow{7}{*}{$\begin{array}{l}\text { - Konsistensi } \\
\text { penggunaan } \\
\text { huruf pada } \\
\text { judul, ada } \\
\text { yang besar } \\
\text { dan kecil } \\
\text { - Sebaiknya } \\
\text { dipakai istilah } \\
\text { Bab bukan } \\
\text { Chapter } \\
\text { - Proporsi } \\
\text { gambar belum } \\
\text { konsisten } \\
\text { - Gambar } \\
\text { sebaiknya ada } \\
\text { sumber } \\
\text { - Kesesuain } \\
\text { indikator dan } \\
\text { latihan, } \\
\text { cermati lagi. }\end{array}$} & \multirow{4}{*}{$\begin{array}{l}\text { - Menyeragamk } \\
\text { an ukuran dan } \\
\text { jenis huruf } \\
\text { pada judul dan } \\
\text { sub judul }\end{array}$} \\
\hline 2 & Urutan sajian & 4 & Baik & & \\
\hline 3 & $\begin{array}{l}\text { Kejelasan uraian } \\
\text { materi }\end{array}$ & 4 & Baik & & \\
\hline 4 & $\begin{array}{l}\text { Kejelasan } \\
\text { ilustrasi/gambar } \\
\text { /contoh }\end{array}$ & 3 & Cukup & & \\
\hline 5 & $\begin{array}{l}\text { Kejelasan } \\
\text { rangkuman }\end{array}$ & 4 & Baik & & $\begin{array}{l}\text { kata Chapter } \\
\text { menjadi Bab }\end{array}$ \\
\hline 6 & $\begin{array}{l}\text { Kejelasan dan } \\
\text { kesesuain } \\
\text { diskusi dan } \\
\text { latihan dengan } \\
\text { indikator }\end{array}$ & 2 & Kurang & & $\begin{array}{l}\text { - Mengatur } \\
\text { ulang gambar } \\
\text { menjadi lebih }\end{array}$ \\
\hline 7 & $\begin{array}{ll}\text { Kejelasan } & \text { dan } \\
\text { kesesuaian } & \\
\text { lembar } & \text { kerja } \\
\text { dengan } & \\
\text { indikator } & \end{array}$ & 3 & Cukup & & $\begin{array}{l}\text { proporsional } \\
\text { - Menambahkan } \\
\text { sumber pada } \\
\text { setiap gambar } \\
\text { - Mendesain } \\
\text { ulang latihan } \\
\text { disesuiakan } \\
\text { dengan } \\
\text { indikator }\end{array}$ \\
\hline Rata & a Penilaian & 3,43 & Baik & & \\
\hline
\end{tabular}

Keterangan:

1. Skor penilaian berinterval 1-5

2. Kriteria:

PS $>4$ (sangat baik); $3<\mathrm{PS} \leq 4$ (baik); $2<\mathrm{PS} \leq 3$ (cukup); $1<\mathrm{PS} \leq 2$ (kurang); dan $\mathrm{PS}=1$ (sangat kurang), PS: perolehan skor.

Sumber: Pengolahan Data Primer

Selanjutnya penilaian dari ahli isi/materi untuk mendapatkan kebenaran materi. Hasil penilaian valiadator disajikan pada Tabel 2 berikut dan secara detail tersaji pada lampiran data

Tabel 2. Hasil Uji Validasi Kelayakan Isi dari Ahli Isi/Materi.

\begin{tabular}{|c|c|c|c|c|c|}
\hline No & Komponen & Skor & $\begin{array}{c}\text { Kategori } \\
\text { Penilaian }\end{array}$ & Masukan & Tindak Lanjut \\
\hline 1 & $\begin{array}{l}\text { Kesesuain KD } \\
\text { dan indikator } \\
\text { dengan materi } \\
\text { setiap bab }\end{array}$ & 4 & Baik & $\begin{array}{l}\text { - Jaga } \\
\text { konsiste } \\
\text { nsi } \\
\text { istilah }\end{array}$ & $\begin{array}{l}\text { Memeriksa } \\
\text { kembali } \\
\text { istilah yang } \\
\text { tidak }\end{array}$ \\
\hline 2 & $\begin{array}{l}\text { Kesesuaian } \\
\text { urutan materi }\end{array}$ & 4 & Baik & & $\begin{array}{l}\text { konsisten } \\
\text { - Peninjauan }\end{array}$ \\
\hline 3 & $\begin{array}{l}\text { Cakupan } \\
\text { uraian materi }\end{array}$ & 3 & Cukup & $\begin{array}{l}\text { - Materi } \\
\text { lebih }\end{array}$ & $\begin{array}{l}\text { kembali } \\
\text { cakupan }\end{array}$ \\
\hline 4 & $\begin{array}{l}\text { Ketepatan } \\
\text { ilustrasi/gam } \\
\text { bar/contoh }\end{array}$ & 4 & Baik & $\begin{array}{l}\text { diperdal } \\
\text { am }\end{array}$ & $\begin{array}{l}\text { materi } \\
\text { - Membuat } \\
\text { diskusi dan }\end{array}$ \\
\hline 5 & $\begin{array}{l}\text { Ketepatan } \\
\text { Geoperspektif }\end{array}$ & 4 & Baik & & latihan lebih \\
\hline
\end{tabular}




\begin{tabular}{|c|c|c|c|c|}
\hline 6 & $\begin{array}{l}\text { Kesesuaian } \\
\text { rangkuman } \\
\text { dengan materi } \\
\text { dan indikator }\end{array}$ & 4 & Baik & $\begin{array}{l}\text { - Ketepata } \\
\text { n diskusi } \\
\text { dan } \\
\text { latihan }\end{array}$ \\
\hline 7 & $\begin{array}{l}\text { Ketepatan } \\
\text { diskusi dan } \\
\text { latihan } \\
\text { dengan materi } \\
\text { dan indikator }\end{array}$ & 3 & Cukup & $\begin{array}{l}\text { perlu } \\
\text { ditingkat } \\
\text { kan }\end{array}$ \\
\hline 8 & $\begin{array}{l}\text { Ketepatan } \\
\text { lembar kerja } \\
\text { dengan } \\
\text { materi dan } \\
\text { indikator }\end{array}$ & 3 & Cukup & \\
\hline & ata Penilaian & 3,62 & Baik & \\
\hline \multicolumn{5}{|c|}{$\begin{array}{l}\text { Keterangan: } \\
\text { 1. Skor penilaian berinterval } 1-5 \\
\text { 2. } \\
\text { Kriteria: } \\
\text { PS }>4 \text { (sangat baik); } 3<\mathrm{PS} \leq 4 \text { (baik); } 2<\mathrm{PS} \leq 3 \text { (cukup); } 1<\mathrm{PS} \leq 2 \text { (kurang); dan } \\
\text { PS= } 1 \text { (sangat kurang), PS: perolehan skor. }\end{array}$} \\
\hline
\end{tabular}

Dari tabel di atas diketahui 5 komponen dinilai baik dan 3 komponen dinilai cukup, secara umum, validator menilai bahwa lembar kerja telah cukup sesuai (skor 3) dengan materi bahan ajar Hidrologi, secara umum bahan sudah sesuai dan dinilai baik (skor 3,62), berdasarkan tabel keputusan termasuk dalam kategori valid dan perlu revisi. Adapun kekurangan yang tertuang dalam masukan, ditindak lanjuti dengan mengikuti saran validator. Hal yang disarankan

Tabel 3. Hasil Uji Validasi Kelayakan Kebahasaan. validator antara lain, menggunakan sumber lain, disamping blog dan Wikipedia. Selain itu, disarankan juga untuk memasukkan hasil-hasil penelitian terkait yang dimuat di jurnal bereputasi, dan penugasan jika perlu ditambah dengan merangkum atau menganalisis jurnal internasional.

Penilaian dari ahli bahasa juga digunakan untuk mendapatkan kebenaran kebahasaan. Hasil penilaian validator disajikan pada Tabel 5.3 berikut.

\begin{tabular}{|c|c|c|c|c|c|}
\hline No & Komponen & Skor & $\begin{array}{c}\text { Kategori } \\
\text { Penilaian } \\
\end{array}$ & Masukan & Tindak Lanjut \\
\hline 1 & $\begin{array}{l}\text { Kemudahan } \\
\text { dibaca }\end{array}$ & 5 & Sangat Baik & $\begin{array}{l}\text { - Induk kalimat } \\
\text { dan anak }\end{array}$ & $\begin{array}{l}\text { - Memperbaiki } \\
\text { kalimat yang }\end{array}$ \\
\hline 2 & $\begin{array}{l}\text { Kejelasan } \\
\text { isi/informasi }\end{array}$ & 5 & Sangat Baik & $\begin{array}{l}\text { kalimat dalam } \\
\text { kalimat }\end{array}$ & dimaksud \\
\hline 3 & $\begin{array}{l}\text { Kejelasan } \\
\text { susunan }\end{array}$ & 4 & Baik & $\begin{array}{l}\text { majemuk } \\
\text { sebaiknya }\end{array}$ & \\
\hline 4 & $\begin{array}{l}\text { kalimat } \\
\text { Ketepatan } \\
\text { penggunaan }\end{array}$ & 4 & Baik & $\begin{array}{l}\text { satu paragraf. } \\
\text { - Istilah asing } \\
\text { dimiringkan }\end{array}$ & $\begin{array}{l}\text { - Memperbaiki } \\
\text { istilah asing }\end{array}$ \\
\hline 5 & $\begin{array}{l}\text { bahasa } \\
\text { Kesederhanaan } \\
\text { bahasa (efektif }\end{array}$ & 4 & Baik & & $\begin{array}{l}\text { - Memperbaiki } \\
\text { jarak panel }\end{array}$ \\
\hline
\end{tabular}




\begin{tabular}{|c|c|c|c|c|c|}
\hline & $\begin{array}{l}\text { dan efisien) } \\
\end{array}$ & & & - Jarak panel & \\
\hline 6 & $\begin{array}{l}\text { Kebenaran } \\
\text { tanda baca }\end{array}$ & 4 & Baik & $\begin{array}{l}\text { kiri dan kanan } \\
\text { terlalu tebal }\end{array}$ & $\begin{array}{l}\text { - Memperbaiki } \\
\text { jarak spasi }\end{array}$ \\
\hline 7 & $\begin{array}{l}\text { Kejelasan } \\
\text { hubungan antar } \\
\text { kalimat }\end{array}$ & 4 & Baik & $\begin{array}{l}\text { - Sebaiknya } \\
\text { menggunakan } \\
\text { spasi tunggal }\end{array}$ & \\
\hline 8 & $\begin{array}{l}\text { Ketepatan } \\
\text { ukuran dan } \\
\text { jenis huruf }\end{array}$ & 4 & Baik & $\begin{array}{l}\text { dan ukuran } \\
\text { huruf } 10\end{array}$ & \\
\hline 9 & $\begin{array}{l}\text { Ketepatan jarak } \\
\text { spasi }\end{array}$ & 4 & Baik & & \\
\hline 10 & $\begin{array}{l}\text { Ketepatan } \\
\text { penggunaan } \\
\text { ilustrasi }\end{array}$ & 5 & Sangat baik & & \\
\hline \multirow{2}{*}{\multicolumn{2}{|c|}{$\begin{array}{l}\text { Rata-rata } \\
\text { Penilaian } \\
\text { Keterangan: }\end{array}$}} & 4,3 & Sangat Baik & & \\
\hline & & \multicolumn{4}{|c|}{ Keterangan: } \\
\hline & \multicolumn{5}{|c|}{$\begin{array}{l}\text { Kriteria: PS }>4 \text { (sangat baik); } 3<\text { PS } \leq 4 \text { (baik); } 2<\text { PS } \leq 3 \text { (cukup); } 1<\text { PS } \leq 2 \text { (kurang); dan } \\
\text { PS }=1 \text { (sangat kurang), PS: perolehan skor. }\end{array}$} \\
\hline
\end{tabular}

Sumber: Pengolahan Data Primer

Dari data tabel di atas diketahui 3 komponen dinilai sangat baik, dan 7 komponen dinilai baik, Lembar kerja dalam bahan ajar Hidrologi dari tinjauan kebahasaan termasuk dalam kategori sangat baik (skor 4,3), nilai tersebut masuk dalam kategori sangat valid dan tidak perlu direvisi. Walaupun demikian, masukan yang disarankan validator langsung diperbaiki, pada catatan akhir penilaian disampaikan juga masalah jumlah pertanyaan, yakni sebaiknya 1 soal memakai 1 pertanyaaan. Kemudian penggunaan kata kompleks yang sejajar, serta kalimat diterangkan dan menerangkan harus diikuti oleh objek. Semua catatan tersebut kemudian digunakan untuk meninjau kembali kalimat kompleks dalam bahan ajar.

\section{b. Uji Formatif (Terbatas)}

Hasil perbaikan draf validasi ahli kemudian diujikan secara terbatas pada 10 orang mahasiswa untuk mendapatkan data kemudahan memahami, keterbacaan, dan kemenarikan bahan ajar. Hasil uji tersebut disajikan pada Tabel 5.4, dan selengkapnya pada lampiran data.

Berdasarkan Tabel 5.4, dari 10 komponen penilaian terdapat 2 komponen yang lebih rendah dari yang lain yaitu kejelasan preview dan mendorong berpikir spasial. Namun secara keseluruhan bahan ajar Hidrologi model dinilai layak digunakan dengan kategori sangat baik (skor 4,62), secara khusus lembar kerja juga pada kategori ratarata sangat baik $(4,5)$, menurut tabel keputusan angka tersebut masuk dalam keputusan sangat valid dan tidak perlu direvisi. Kalimat pada preview yang kurang jelas diperbaiki, agar fungsinya sebagai pengaktif pengetahuan awal dapat maksimal. Mendorong berpikir spasial tidak dilakukan perbaikan, karena pengorganisasian yang terkait dengan berpikir spasial disajikan 
secara merata dari penyajian materi sampai dengan penugasan.

Tabel 4. Hasil Uji Formatif

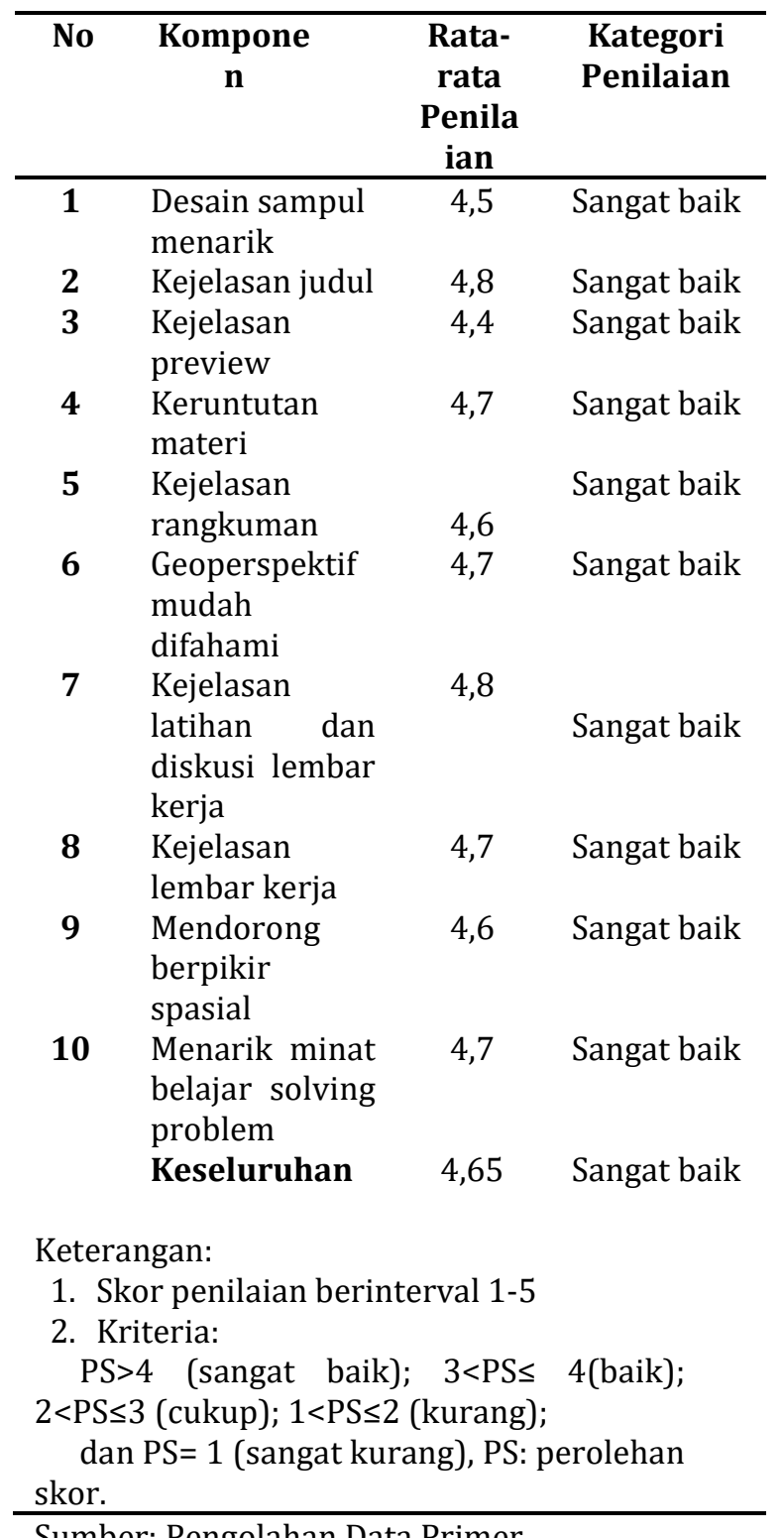

Sumber: Pengolahan Data Primer

\section{KESIMPULAN}

Hasil pengembangan model lembar kerja spatial thinking to solving problem dianggap menarik dan mendorong belajar aktif terutama berpikir bagaimana menyelesaikan suatu permasalahan, serta siap dan layak digunakan

\section{DAFTAR PUSTAKA}

Astutik, S., Susantini, E., Madlazhim, Nur, M. 2017. Effectivness of Collaboratif Students Worksheet to Improve Student's Affective Scientific Collaborative and Science Process Skills (SPS). International Journal of Education and Research, 5 (1), 151-164.

Ayva, O. 2012. Developing Student's Ability to Read, Understand and Analyze Scientific Data Through The Use of Worksheets That Focus on Studying Historical Documents. Procedia Social and Behavioral Sciences 46 (2012'[), 5128 - 5132.

Bakirci, H., Bilgin, A., K., Simsek, A. 2011. The Effects of Simulation Technique and Worksheets on Formal Operational Stage in Science and Technology Lessons. Procedia Social and Behavioral Sciences 15 (2011), 1462-1469.

Bellawati, Tian, dkk. 2003. Pengembangan Bahan Ajar. Jakarta: Pusat Penerbitan Universitas Terbuka.

Beauchamp, Y., \& Yousesef, A. 1998. An Effective Approach to Design of Experiment (DOE) Using Calculation and Analysis Worksheet and Computerised Spreadsheet. Computer and Industrial Enginering, 35(3-4), 643-646. http://dx.doi.org/10.1016/S 0360-8352(98)00179-X.

Biddle, D.S., Shortle, D. 1969. Programme Planning in 
Geography. West Como: The Martindale Press.

BIG, 2015. Peta, Representasi Spatial Thinking dari Sudut Pandang Implementasi Informasi Geospasial. Online: http://www.bakosurtanal.go. id/berita/ Peta, Representasi Spatial Thinking dari Sudut Pandang Implementasi Informasi Geospasial. Akses 21 Mei 2017.

Crespo, M., \& Pozo, J. J. 2004. Relationship between Everyday Knowledge and Scientific Knowledge. Understanding How Matter Change. International

Journal of Science

Education, 26(11), 1325-

1343.http://dx.doi.org/10.10 80/0950069042000205350.

Dhajiri, Kosasih, A. 1985. Strategi Pengajaran Afektif-NilaiMoral-VCT dan Games dalam VTC. Bandung : Jurusa PMPKn IKIP.

Dick, W., Carey, L. Carey, J. 2001. The Systematic Design of Instruction. NY:Longman, Inc.

Diknas, 2004. Pedoman Umum Pemilihan dan Pemanfaatan Bahan Ajar. Jakarta: Ditjen Dikdasmenum.

Fauvel, John; Maanen, Jan; van Maanen, J.A. 2000. History in Mathematics Education: An ICMI Study. Springer Science \& Business Media. p. 216.

Gabler, R., Petersen, J., Trapasso, L. 2007. Essentials of

Physical Geography.

Thomson Higher Education USA. 8th Edition.
Gulo, W. 2002. Strategi Belajar Mengajar. Jakarta : PT. Grasindo.

Karsli, F \& Sahin, C. Developing worksheet based on science process skills: Factors affecting solubility. AsiaPacific Forum on Science Learning and Teaching, 10 (1), Article 15, p.1.

Khafid, S. 2013. Pengantar Geografi. Surakarta: UNS Press.

Kibar, Z., B., Ayas, A. 2010. Implementing of a Worksheet Related to Physical and Chemical Change Concepts. Procedia Social and Behavioral Sciences 2 (2010), 733-738.

Kolomuc, A., Ozmen, H., Metin, M., Acisli, S. 2012. The effect of animation enhanced worksheets prepared based on $5 \mathrm{E}$ model for the grade 9 students on alternative conceptions of physical and chemical changes. Procedia Social and Behavioral Sciences, 46 ( 2012 ), 1761 1765.

Linsley, R,K. 1975. Applied Hydrology. New Dehli: McGraw-Hill Publishing Company Ltd.

Lombok Post, 2017. Jerowaru Masih Kekurangan Air Bersih. Online, http://www.lombokpost.net/ category/ntb/selong/jerowa ru_masih_kekuran gan_air_besih. Di akses 20 Mei 2017.

Metoyer, S \& Bednarz, R. 2017. Spatial Thinking Assists Geographic Thinking: 
Evidence from a Study Exploring the Effects of Geospatial Technology,

Journal of Geography, 116(1), 2033.

NRC. 2006. Learning to think spatially: GIS as a support system in the K-12 curriculum.Washington, D.C.: The National Academies Press.

Prastowo, A. 2011. Panduan Kreatif Membuat Bahan Ajar Inovatif. Jogjakarta:DIVA Press.

Rahmi, Aggraini, V., Melisa. 2014. Pengembangan Lembar Kerja Mahasiswa Berbasis Problem Based Learning Pada Perkuliahan Persamaan Deferensial Biasa. Proseding Seminar Nasional Sains dan Pendidikan Sains IX, 5 (1), 864-869.

Scholz, M. A., Huynh, N. T., Brysch, C. P., \&Scholz, R. W. 2014. An Evaluation of University World Geography Textbook Questions for Components of Spatial Thinking. Journal of Geography, 113(5), 208-219.

Subhani, A. 2017. Silabus Hidrologi Dasar. Selong: Program Studi Pendidikan Geografi Universitas Hamzanwadi.

Subhani, A., Utaya, S., Astina, I., K. 2017. Engage Spatial Thinking in Geography Teaching Material. International Journal of Academic Research in Business and Social Sciences, 7(5), 33-42.

Sumarmi, 2012. Model-model Pembelajaran Geografi.
Malang: Aditya Media Publishing.

Trewet, B., C., Pharm., Fjortoft, N. 2013. Evaluation of the impact of a continuing professional development worksheet on sustained learning and implementing change after a continuing pharmacy education activity. Research in Social and Administrative Pharmacy, 9 (2013), 215-221.

Utami, W., S., Sumarmi, Rudja, I., N. 2016. The Effectiveness of Geography Student Worksheet to Develop Learning Experiences for High School Students. Journal of Education and Learning, 5(3), 315-321. 